\title{
DESIGN OF PROTOTYPE ELECTRICAL FIRING DEVICE SMOKE POWDER BOMB INTEGRATED IN ANDROID
}

\author{
Endin Tri Hartanto, Bagus Irawan, Sunarta, Atet Saputra \\ Indonesia Naval Technology College, STTAL Surabaya Indonesia
}

\begin{abstract}
Threats are any businesses and activities, both from domestic and foreign countries which are considered endangering the Indonesian sovereignty, the territorial integrity of the country, and the safety of the whole nation. Military threats are threats that use organized armed forces that are judged to have abilities that jeopardize the country's sovereignty, the territorial integrity of the country, and the safety of the whole nation. This smoke powder firing system is to utilize the internet network so that to trigger the smoke powder bomb can be carried out from various places and anywhere the smoke powder weapons ignition can be carried out. Design and Composite Smoke Powder as a Marine, Air and Ground Defense Sabotage Weapon. This research is expected to be able to contribute to sabotage cysts and deception of opponents. The main objective in the design of the building of Smoke Powder as a means of supporting smoke bomb training in a pattern to trick the enemy. In planning the bomb lighter system uses an electric lighter which is controlled remotely via an Android phone call. The lighters used are gas stove lighters with 3 Volt dc battery voltage source. So that the microcontroller device can regulate the flow of current to the lighter, the author uses a transistor that functions as switching power sources to the lighter. The command for switching resources to a lighter is obtained from the command of an Android device. The test results show the system can work well, even though the constraints occur in the system, namely the GSM network which often interrupt.
\end{abstract}

Keywords : Smoke powder, switching, Android, GSM.

\section{INTRODUCTION}

The Navy in this case the Marine Corps as a means of national defense in maintaining national sovereignty must be supported by adequate defense equipment for the landing area and its borders, the Marine Corps has the duty to guard and secure it, especially for Marine soldiers serving in the border and at Yonmarhanlan.Marines in their main duties carry out the duties of Base Defense.

Threats are all forms and actions, both from within the country and abroad that are considered to threaten the integrity of the state, and the safety of the whole country. Military threat is a movement that uses all weapons considered to have the ability to undermine the country's sovereignty, the territorial integrity of the country, and the safety of the whole nation Military threats can take the form of: Aggression by other countries, territorial violations. espionage, sabotage, armed terrorism, armed rebellion and civil war.

Sabotage is a planned, deliberate and silent destruction of equipment, personnel and activities of the target field to be destroyed in the midst of society, destruction must have a great psychological effect. Smoke powder bomb is a type of weapon that functions to sabotage, harbor and paralyze opponents. This weapon is designed by formulating a number of chemical compounds so that it can emit smoke which serves as a phishing and as an annihilation of an opponent.

The main objective in the design of the building of Smoke Powder as a means of supporting smoke bomb training in a pattern to trick the enemy.The design of Smoke Powder implements a microcontroller as a process unit, a GSM modem as a data communication unit and an Android device to trigger a bomb.

The development of current mobile phone technology that has advanced very rapidly, presumably can be one of the device options that can be used to trigger smoke bombs through telephone calls. Handheld phone devices based on the Android operating system become one of the good options, considering that Android is an open 
source so that everyone can develop applications on this device.

The system that can be used to trigger smoke bombs is through telephone calls. A simple choice in the application of the bomb trigger system, the authors chose to use telephone calls. The basic reason in the selection was because a telephone call could inform whether the modem device installed in the bomb was active or not. The ring tone that appears can tell this.

For this reason, in this study the author will create an Android Integrated Electric Smoke Bomb Powder Prototype Firing Device Design that functions to trigger the Smoke Bomb to explode. The use of firing devices originating from voltage-increasing transformers is sufficient to meet the need to trigger a smoke bomb. With a voltage source around 4000 VDC so that it can be applied in portable and small-sized forms. In realizing a lighter-controlled flame system, the author tries to raise it to be a research theme with the research title Design of Prototype Electrical Firing Device Smoke Powder Bomb Integrated in Android.

In this study, it is necessary to formulate the problems. Some of these problems are:

a. How to develop Bomb Bomb smoke trigger system technology that is controlled through an Android device to replace a conventional trigger system.

b. How to develop a control system utilizing Android phone technology to replace old cell phone technology.

The objectives of Design of Prototype Electrical Firing Device Smoke Powder Bomb Integrated in Android are:

a. Design and develop Bomb powder trigger smoke system technology that is controlled through an Android device to replace conventional trigger systems. b. Develop a control system utilizing Android smartphone technology to replace old cell phone technology.

The benefits of Design of Prototype Electrical Firing Device Smoke Powder Bomb Integrated in Android are:

a. As the application of a smoke bomb firing system using an electric lighter.

b. As the application of Arduino programming material.

c. As the application of Android programming material.

d. As the application of communication between Android devices and Arduino devices via telephone calls.

\section{RESEARCH METHODS}

\subsection{Research design}

Design of Prototype Electrical Firing Device Smoke Powder Bomb Integrated in Android is a design research consisting of several steps to achieve the ultimate goal of a design and manufacture of a cigarette lighter system for smoke bombs. The smoke bomb used is a means of supporting training in deceiving enemies. The source of the smoke produced results in obstruction of enemy sight.

\subsection{Research procedure}

To carry out the research properly, the preparation of steps to find the source of the data and research of Design of Prototype Electrical Firing Device Smoke Powder Bomb Integrated in Android that includes research instruments, primary data, secondary data, as well as testing the validity and reliability of the data.

\subsection{Research Time and Place}

The research site is a place where the research will be conducted. The research conducted by the author took place at the Moro Krembangan STTAL Campus in Surabaya. The 
time used in this study began in July 2019 until the end of December 2019.

\section{DESIGN, IMPLEMENTATION AND TESTING OF THE SYSTEM}

In this system will describe the design of the system that was made as well as analysis and testing based on the design that has been made. Gradual tests are carried out to ensure that the outputs are in accordance with the design goals. If it is found that the results of the test are not appropriate, a repair and improvement will be carried out in terms of hardware and software.

To get a good smoke bomb performance, the GSM shield module needs to get a GSM signal that is strong enough and good. GSM is an international standard for cellular phones.GSM is an abbreviation which is short for Global System for Mobile Communications Which is sometimes referred to as $2 \mathrm{G}$, because it is a second generation cellular network. GSM supports outgoing and incoming voice calls, Simple Message Systems (SMS or text messages), and data communication (via GPRS). The Arduino Shield GSM module is a GSM modem. From a cellular operator's perspective, the GSM Shield Arduino module looks like a cellphone.

From an Arduino perspective, the Arduino GSM Shield Module looks like a modem. To access the network, all you have to do is subscribe to a cell phone operator, a GSM-compatible device such as a Subscriber Identity Module (SIM) card. Network operators provide a SIM card, which contains information such as cellphone numbers, and so on. The main key to controlling smoke bombs is the GSM network, because in the trigger process to ignite the smoke bomb, the command is carried out via telephone calls.

\subsection{Design of Smoke Bomb System}

In the smoke bomb system design is explained in the circuit block diagram in Figure 4.1. Configuration relationships between circuits or modules are explained in relation to the Arduino Mega 2560 pins with the GSM shield module, relay module, fire trigger module and battery. As the main source of battery power, the writer uses 18650 2 units of battery which are arranged in series as a source of Arduino power supply, GSM shield, relay and fire trigger. In determining the GSM shield power supply source, the writer studies based on the minimum and maximum voltage limits suggested in this module.

The supply source is for GSM Shield work, the power supply source is connected to the Arduino Mega regulator output which produces a voltage output of $5 \mathrm{~V}$, this value is sufficient to run the GSM Shield module. As has been known before that the GSM Shield module can not work with less than $4.1 \mathrm{~V}$ and no more than $5 \mathrm{Vdc}$. Voltage outside the permitted limits will automatically cause the GSM module to shutdown .

In designing the control system for triggering smoke bombs, the writer uses an Android smartphone. This device was chosen because Android is an open source, so everyone can develop applications on this operating system. The programming language chosen using Java with the editor of the program used is Android Studio.

To run an application or software that runs using the Java platform, it is necessary to add a java engine, which must be installed on a computer or laptop operating system. Because the author uses the Windows 864 bit operating system, then the chosen java engine is the 64 bit version, namely java jdk 1.8.2 64 bits. Without this java engine, Android Studio cannot run.

Figure 1 below is a block diagram of a smoke bomb system design . 


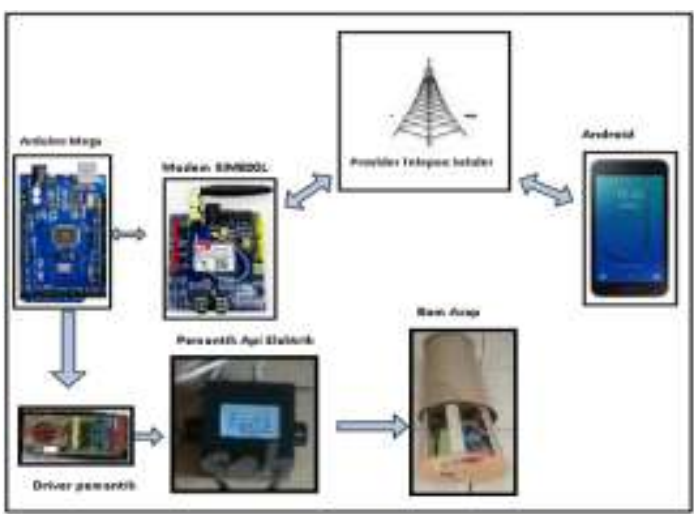

Fig.1 Block diagram of a smoke bomb system design

As an application to trigger smoke bombs, the authors designed an application on Android using the Android Studio program.Applications designed on the design of this using the Java programming language, to be able to explain the system are made can be seen in interface design system in Figure 2. Android app. In this design the author uses the button component interface to trigger smoke bombs. Pressing the button will make the system to make phone calls to the smoke bomb device..

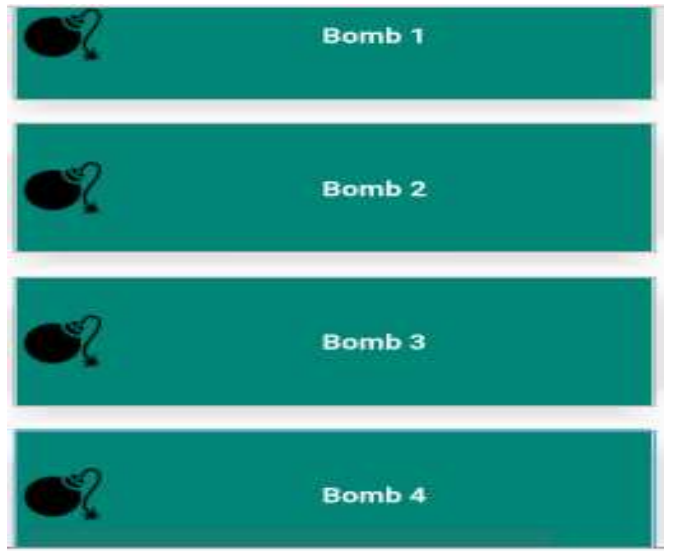

Fig.2 Smoke Bomb Application Interface Design

Application interface images can be written in the form of $x m l$ layout, which can explain the interface in the form of program code. The following program code is the $\mathrm{xml}$ code of the Android application interface design.

Based on the program code display interface system telephone number settings can be seen system interface in the form of graphical system interface settings in Figure 3.

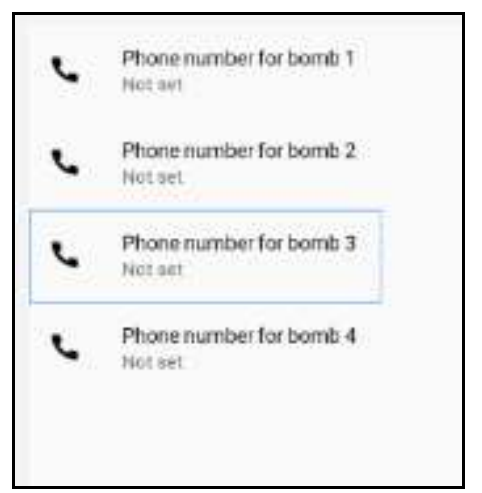

Fig.3 Interface of the Telephone Number Management Program

\subsection{Implementation}

For the implementation of the smoke bomb system, some of the things that must be done are as follows :

a. SIM card

Communication providers that provide SIM must also provide GSM signal coverage at the location of the smoke bomb. SIM cards usually have a four digit PIN number associated with the provider for security purposes.PIN number is needed to connect to the network. Some SIM cards become locked if the PIN code entered is incorrect.

\section{b. GSM Shield Module}

GSM is a global standard for cellular communication. GPRS or also called General Packet Radio Service. GPRS is a cellular service on $2 \mathrm{G}$ and $3 \mathrm{G}$ cellular communications. $\mathrm{A}$ GSM shield is required to connect the device to the cell phone network. In its application the GSM Shield module has a feature compatible with Arduino and can receive telephone calls and produce output throughcommunication channels if there is an incoming call.

c. Voltage boost module

Can sprinkle fire which has to do to ignite the smoke bomb wick, so a circuit or module is needed to increase the voltage from a $3-5 \mathrm{~V} \mathrm{DC}$ voltage to $4000-5000 \mathrm{Vdc}$. At this voltage point value, the distance of the two poles adjacent to each other can spark fire. Sparks are an electron jump from 
positive to negative, with a high voltage value, the electrons can flow through the air.

\section{d. Relay module}

The module is used in the smoke bomb system to ignite and boost the voltage-raising module.If there is an incoming call, Arduino will order the relay to turn on.With the position of the relay on, the source of the power supply to the voltage rises is flowed, which results in sparks on the fire trigger terminal

\subsection{Testing}

\subsubsection{Testing of GSM Shield Module}

To start testing the GSM shield module, it is necessary to perform a GSM shiled device as shown in Figure 3.4.In general, a valid SIM card that is compatible with the GSM Shield module is required. For testing, use the power source from the USB port that is connected to the computer device. For initial testing can be done using the AT + command to view data communication between the GSM Shield module with the Arduino Mega 2560. If the GSM Shield module responds to commands from the Arduino Mega then the "Monitor" returns appear "OK".

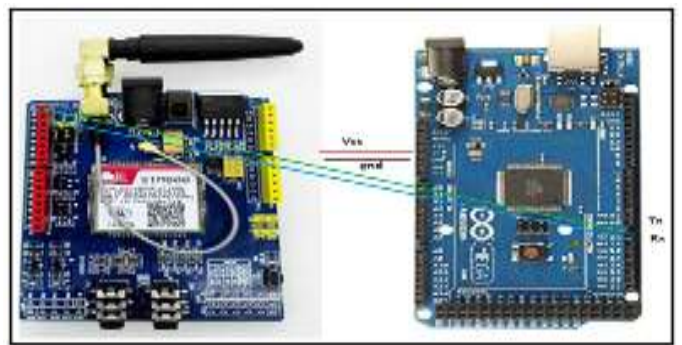

Fig.4 Series of GSM Shield Module Testing

The code for testing the GSM Shield response module can be written with the following program code:

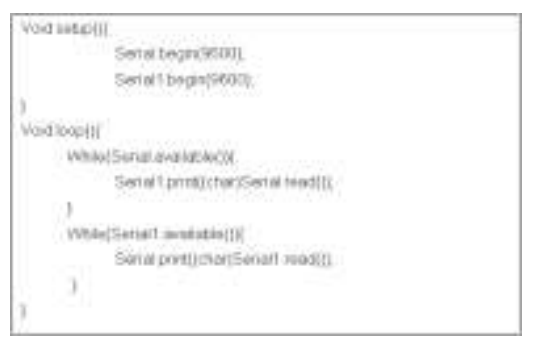

Select the 19200 baud rate setting on the monitor terminal and choose a carriage return. Write the AT command in the data sending box and press enter. As shown in Figure 5 follows:

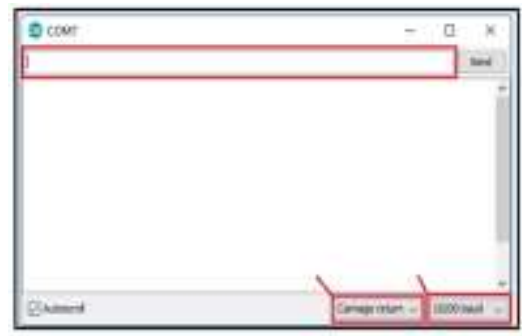

Fig.5 GSM Shield Module Response Testing Process

Figure 6 below is the result of testing the GSMShield response module. If the GSM module responds it will reply with OK information.

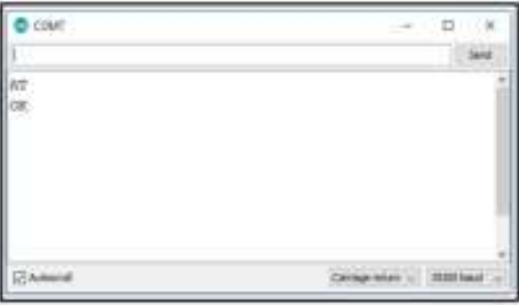

Fig.6 GSM Shield Module Response Test Results

From these tests it can be concluded that the GSM Shield module is well connected to the Arduino Mega 2560 device. Tests to detect incoming calls in the next test, contained in the following test figure 7 :

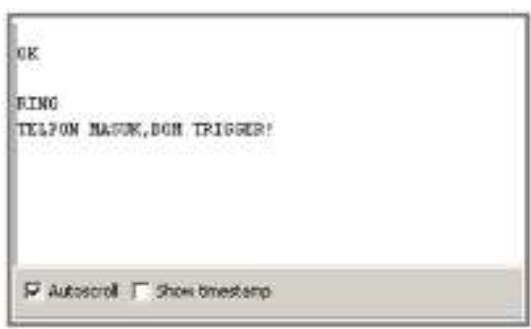

Fig.7 Connection to the Arduino Mega 2560

Figure 8 is a device that tests the system response to the at command test on the GMS Shield module. 


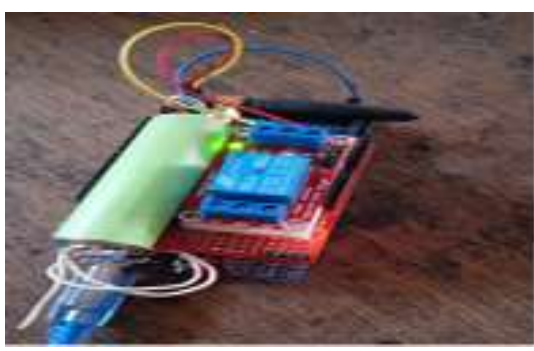

Fig.8 Image of the GSM Shield Response Test Device

Figure 9 below is a picture of a smoke bomb test device on an incoming call test via an Android device

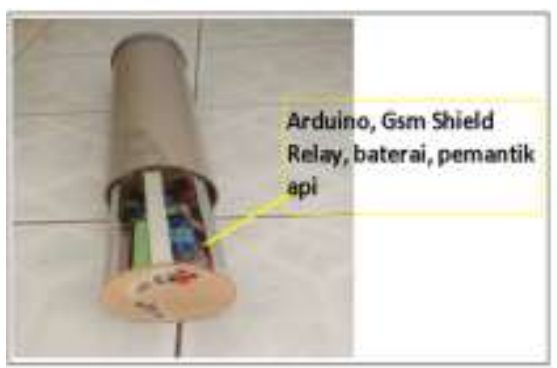

Figure 3.9 Figure of Testing Device for Phone Calls Through an Android Device

\subsubsection{Testing the Application Interface}

In testing Android applications, applications that have been made on the Android Studio program, run on Android devices. Android application testing requirements that a GSM telephone network must be available. and the availability of credit to make calls. The initial Android application must be installed on the device, to uninstall the application that has been made can be done by debugging the system directly from the $\mathrm{PC}$ to the Android device via a USB cable, the Android Studio program can be installed by running the RUN command on the Android studio console.

In testing telephone calls can be explained in the test image on an Android device, as shown in the following test pictures.

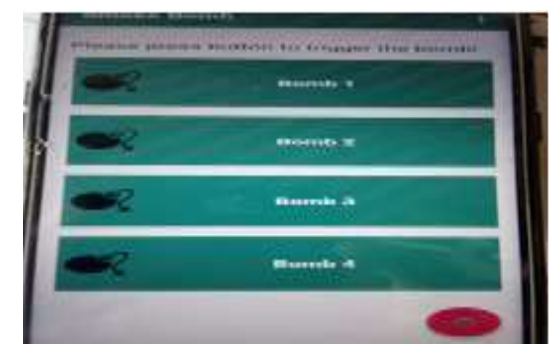

Fig.10 Interface Display Android Application
Testing setting the telephone number stored in the inter $\mathrm{n}$ Android devices, can be seen on the following Android application testing :

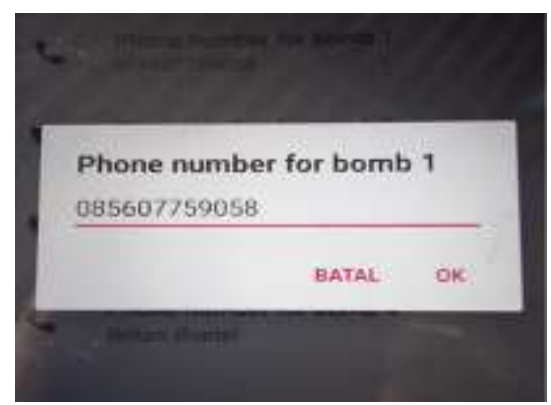

Fig.11 Display Android Application to Store Phone Numbers

\section{CONCLUSIONS}

The conclusions obtained from The Design of Prototype Electrical Firing Device Smoke Powder Bomb Integrated in Android can be stated as follows:

a. The selection of android mobile phone features as a trigger for bombs through phone calls can replace conventional trigger systems.

b. The use of a smoke bomb trigger control system using an android mobile phone is better than the old cellular phone because an android cell phone has sophisticated application features.

Based on the research results of the smoke bomb design that has been done, it can be given a suggestion for further system development. These suggestions are:

a. Develop a control system using a private internet network to avoid hacking and hacking.

b. Develop a system that can provide feedback to the control device in the event of a trigger failure in the smoke bomb.

\section{REFERENCES}

Andrianto $\mathrm{H}$ and Aan Darmawan 2016. Arduino Fast Learning and Programming. Bandung, Bandung Informatics.

Arduino. 2019, July. Arduino Mega 2560 http://arduino.cc/en/Main/arduinoBoardMega 2560.

Dony Hendra Lesmana, M. Rif'an, S.T., M.T. and Ir. Nurussa'adah, M.T. 2015. Designs and Builds a Gps-Based Vehicle Speed 
Monitoring System with SMS as Data Transmission Media.

Djuandi, Fer,i 2011. Introduction to Arduino. Jakarta: Elexmedia Publisher

Kadir, Abdul, 2015. A Study Guide for Various Microcontroller Based Projects. Yogyakarta: ANDI Publisher.
Primayuga, Ghana, 2018. Design and Build Data Communication System Trainer Using Arduino Nano. Surabaya. STTAL.

Wildan Maulana, M. Kamal, Azhar. 2016. Design and Control of On / Off Automatic Gas Stove Lighters in Plastic Processing Machines to Become Microcontroller-Based Fuel Oil. 